\title{
Road Infrastructure and Road User's Satisfactions: A Case Study of Motorway Route 7, Thailand
}

\author{
Suthathip Suanmali ${ }^{1}$, Kasidis Chankao ${ }^{2}$, Veeris Ammarapala ${ }^{3}$ \\ 1,2,3 Transportation Research Center, Sirindhorn International Institute of Technology, Thammasat \\ University, Pathum Thani 12000, Thailand
}

\begin{abstract}
The development of tourism in Thailand relies on the development of appropriate infrastructure. Road access is the key infrastructure issue for tourist destinations throughout Thailand. Each year Thailand has welcomed over 15 million travelers, accounted approximately $7 \%$ of GDP. To support tourist activities, variety types of transportation modes have designed. However, road transportation is one of the most effective modes that connect most places together. Beside high-standard vehicles, road is another mechanism that derive comfort and safety of travelling. For this reason, Motorway networks were initiated and constructed to support high speed traffic with high safety and standard. Motorway route 7 is one of major motorway networks that lies between major cities and tourist landmarks. To raise the road standard could be the key to support tourist industry and economic growth. The road developments may not be precise and accurate without knowing the needs from road users'. Therefore, a questionnaire is developed and distributed to 890 randomly selected road users along Motorway route 7 . Factor analysis and $t$-test are employed to analyze the factors affecting road users' satisfaction and to compare the satisfaction level between both inbound and outbound travelers.
\end{abstract}

\section{Introduction}

Tourism industry is one of the major industries in Thailand which accounted 825.6 billion baht or $7.3 \%$ of total GDP in year 2012, and is forecasted to constantly rise by $6.8 \%$ of total GDP each year until year 2023 [1]. To support the expansion of this industry, infrastructure development may be needed. Department of Tourism (DOT) is an organization that is responsible for supporting and developing tourism industry under its vision to "Support and develop tourism industry to reach international standard and to be central of Asia tourism" [2]. The travel and tourism competitiveness report in 2013 has ranked the tourism infrastructure of Thailand as the $31^{\text {st }}$ out of 140 countries worldwide, also reported the keys of attracting travels from around the world to Thailand are natural resources and strong affinity for travel and tourism [3]. The communication from place to another may need to rely on transportation system; such as air, marines, trains, and roads.

However, with traveling inconvenience or deterioration of transportation infrastructure may lead to reduction of attractiveness from travelers. The transportation infrastructure development of Thailand has been highly prioritized from transportation authorities to raise the standard; as a result both air and 
ground transportation infrastructures of Thailand are ranked in the $21^{\text {st }}$ and the $62^{\text {nd }}$ respectively from 140 countries worldwide [3]. For this we see the opportunity to further develop and improve on Thailand's transportation system; in particular, land transport and highway network systems. Because road and highway networks are one of the most important infrastructures for both domestic and oversea tourists as the networks connect most places together. They are the main routes in networks linking regions, provinces, and districts. However, the deterioration of road surfaces can decrease serviceability, and such deterioration is mostly influenced by traffic. The inconvenience of travel may bring the reduction of travel demand and create an unsafe situation for travelers to commute and lead to failure of creating impression for future return. Good roads are the route to promote and enhance economic development such as vacations, shopping and entertainment. Moreover, the studies of Andrijcic, Haimes, and Beatley [4] has pointed that a consequence of failing transportation infrastructure may create the following concerns: reduced safety of travelers, high transportation cost, congestion and dissatisfaction to road users. For these reasons, the assessment of road infrastructure and road users' satisfaction should be done to identify the users' perception to the service for future development.

Department of Highways (DOH) is an organization that is responsible for constructing and maintaining most of highway networks in Thailand. Both DOH and DOT work in parallel to help the DOT accomplish its mission to raise travel standard within the country. One of the more efficient highway networks in Thailand is the motorway network system. It is a high performance road that is able to support high traffic flow with safety and comfort and is very convenience to travel on this motorway. Motorway route 7 is one of the oldest motorways in Thailand; its lie between major cities passing through many tourist landmarks such as Suvarnabhumi International Airport, Pattaya City, and Bangkok. It has a minimum of junctions and allows traffic to flow at higher speeds. Under the $\mathrm{DOH}$, the Inter City Motorway Division is the main highway organization that is responsible for maintaining and developing motorway network. One of their missions is to maintain roads and bridges along the motorway to enhance safety, provide mobility, and ensure a usable transportation system for everyone.

This study is the extended study on Motorway route7 road users' satisfaction assessment. The earlier study identified factors affecting road users' satisfaction by using multiple regression technique. On this research, the objective is focused on whether there is a significance difference on satisfaction between inbound and outbound road users. The result of this study is expected to be used as a guideline for highway authorities to develop a suitable plan for maintaining the service to road users at the highest level [5].

\section{Literature Review}

The study on tourism industry development in Mauritius, Southeast Coast of Africa, has shown that in order to gain attractiveness from travelers, one must know factors of attraction. Several methods method has been done from the study and found out that Mauritius tourism product is normal goods and the efficient of transportation infrastructure is the concern to travelers. Moreover, accommodation capacity is one of the key to influence airlines to establish routes to the country [6].

Another study has pointed out that Prioritization of Travel and Tourism, Air Transportation Infrastructure, Ground Transportation Infrastructure, and Tourism Infrastructure are factors that create nation's competitiveness [3]. Among the four factors Ground transportation infrastructure especially road transportation is one of the major concerns as the significant growth in transportation demand with maintenance failures can cause increase in transportation cost and time, reduction in traveler's safety.

The development of infrastructures from government authorities alone may not give out the accurate development direction. To impose the accurate and precise solutions, authorities do need involvement from users. Suanmali, Ammarapala, and Chankao [7] have stated "Road users are customers who use the service, and they should have involvement in improving the service level". They can identify needs, and those needs could create fulfillment of wishes called "satisfaction". 
Therefore, understand and follow the needs are essentially to create satisfaction". According to Sakai, Yamada-Kawai and Matsumoto [8] have stated customer satisfaction level has to be fulfilled by the service provider.

The road satisfaction assessment may be a new topic to Thailand, while many developed countries have done similar studies and found appropriate factors to be emphasized in order to create road users satisfaction. It is important for future development to understand how road users satisfy with the road services. In addition, Wardhana, Ishibashi, and Kiyota [9] have studied about road users' satisfaction on national road number NR-203 and NR-35 of Sagam, Japan. The study examined from the two groups of short distance and long distance road users on the following categories: safety equipment, smoothness of road surface, travel time, rest area/ road facilities, government service level, and overall satisfaction towards the road. The result pointed out that factor affecting road users' satisfaction from both groups smoothness of road surface and rest area/road facilities. Moreover, the study applied statistical techniques of multiple regression and factor analysis to identify factors affecting the road user satisfaction. In addition, the study of Karnataka State Highway Improvement Project [10] emphasized on factors affecting road users' satisfaction by asking the respondents to indicate their satisfaction level on each attribute to the basis of five-point Likert scale. The result from using multiple regression indicated that road conditions and road facilities are significant factors that can create higher satisfaction from the road users in Karnataka State.

In this study factor analysis and t-test are employed to analyze is there is a significant different is the mean satisfaction level for both inbound and outbound road users. This result is expected to serve as a guideline for highway authorities to develop a precise strategic plan on each bound.

\section{Methodology}

Two research methods are employed in this study. One is documentary research from literature surveys, journals, articles, and previous research works. These data are collected from research published in credible international journals. Second is survey research. Surveys are done by means of questionnaire surveys for tourists and road users who use motorway route 7 during two periods: first period from October 28 to November 10, 2013 and second period from December 3 to December 9, 2013. Each day, the survey is conducted from 9AM to 6PM and is taken place at the service areas of both in-bound and out-bound directions. These service areas are equipped with service facilities of gas stations, public toilets, local and fast-food restaurants. In the questionnaire we have divided into two main parts; the first part is asking about the information on socio-economic (e.g. gender, age, income, etc.) and behavioral of road users. The second part is a set of closed ended questions that attempts to address the overall satisfaction of travelers in each category. The categories mentions in the questionnaire set are developed based on the characteristics of Motorways route 7 and previous studies mentioned in literature review. They are value and time for money, safety, comfort, amenities, distance signs and road markers, and road conditions. Each respondent is asked to indicate their satisfaction level in each category based on five-point Likert scale where; $5=$ Very satisfied, and $1=$ Very dis-satisfied.

\section{Analysis and Results}

This study questionnaire was randomly distributed to 890 samples randomly. Based on the samples, demographic information can conclude that $31.80 \%$ of them regularly travel during $9.01-11.00$ a.m. Second, $74.83 \%$ of respondents are traveling outbound from Bangkok to Chonburi. Third, 37.19\% of them indicates that they are between 18 to 27 years old, and $56.29 \%$ of them drive or use regular personal vehicles, followed by $32.47 \%$ of them use public transportation (taxi, coach). Lastly, $28.76 \%$ of the respondents are traveling on this motorway once a month. Travel time reduction has rated at the highest satisfaction level on in-bound direction at the mean score of 3.49 , while the outbound direction 
has rated at the mean score of 3.60. Public toilet is an attribute that receives the lowest satisfaction level. The average satisfaction of public toilets is 2.46 for in-bound road users and 2.63 for out-bound road users. They are dissatisfied about the cleanliness of the public toilets.

The factor analysis are done to reduce the dimensions of independent variables and its summary of is shown on table 1 . Then the independent $t$-test is used to compare the satisfaction level between inbound and outbound road users where hypothesis is set up as

$\mathrm{H}_{0}=$ Respondents on both directions percept the equal attitude of satisfaction

$\mathrm{H}_{1}=$ Respondents on both directions percept the different attitude of satisfaction,

The $t$-test is run on each of the item indicated on table 1. In addition, Levene's test is applied to see the homogeneity of variances whether they are assumed equal or non-equal.

Table1. Statistical Information from the Analysis

\begin{tabular}{lccc}
\hline & Mean & Mean & Factor \\
Factors & in-bound & out-bound & Loading
\end{tabular}

FACTOR 1: Signs/traffic/warning and road marking $(0.887)^{a}$

1.1 Number of traffic signs

1.2 Accuracy and clarity of traffic signs

1.3 Number of emergency telephone number signs

1.4 Warning signs when the lanes are closed

1.5 Visibility of road markers

FACTOR 2: Convenience $(0.857)^{a}$

2.1 Number of tollbooths at each tollgate

2.2 Smoothness of road surface

2.3 Number of lanes

2.4 Lane width

2.5 Location of each interchange

FACTOR 3: Amenities $(0.874)^{a}$

3.1 Number of public toilets

3.2 Cleanliness of public toilets

3.3 Convenience to reach service area

3.4 Safety in service area

$2.9058^{b}$

$3.1570^{b}$

0.615

$-3.657 * * *$

FACTOR 4: Value for Time and Money $(0.833)^{a}$ 
4.1 Speed and accuracy of toll fees officers

$\begin{array}{llll}3.4144^{b} & 3.4488^{b} & 0.707 & -0.593^{*} \\ 3.4866 & 3.6033 & 0.717 & -2.004^{* *} \\ 3.2646^{b} & 3.4438^{b} & 0.673 & -3.066^{* * *} \\ 3.1205 & 3.2816 & 0.723 & -2.508^{* * *}\end{array}$

4.2 Traveled time

4.3 Fuel consumption

3.1205

3.2816

FACTOR 5: Conditions $(0.833)^{a}$

5.1 Traffic volume

$3.0446^{b}$

$3.2127^{b}$

0.798

$-2.643 * * *$

5.2 Cleanliness of road surface

$3.1607^{b}$

$3.4148^{b}$

0.686

$-4.098 * * *$

5.3 Characteristics of Motorway Route 7

$3.3632^{b}$

$3.5204^{b}$

0.562

$-2.488 * *$

5.4 Legality of other drivers

$3.0897^{b}$

$3.2021^{b}$

0.685

$-1.887^{*}$

FACTOR 6: Speed of Safety Staff $(0.814)^{a}$

6.1 Speed in managing the accidental area by officers

$\begin{array}{lll}3.0507^{b} & 3.2524^{b} & 0.778\end{array}$

$-3.535^{* * *}$

6.2 Speed of emergency responses

$\begin{array}{llll}3.0963^{b} & 3.2480^{b} & 0.771 & -2.529^{* *}\end{array}$

FACTOR 7: Safety Equipment \& Environment $(0.721)^{a}$

7.1 Controlling of transportation vehicles

$\begin{array}{llll}3.0045^{b} & 3.1762^{b} & 0.511 & -2.596^{* * *} \\ 3.3036^{b} & 3.4615^{b} & 0.526 & -2.550^{* *} \\ 3.0982^{b} & 3.2674^{b} & 0.639 & -2.566^{* *}\end{array}$

7.2 Safety equipment

7.3 Light at night

3.0963

3.2480

\footnotetext{
${ }^{a}$ Reliability score (Cronbach's $\alpha$ ) for each factor grouping is shown in parentheses.

${ }^{b}$ The variance of satisfaction between direction is not equally assumed.

${ }^{*} p<0.10,{ }^{* *} p<0.05$, and ${ }^{* * *} p<0.01$
}

\section{Discussion}

The results shown in table 1 indicated that the mean satisfaction level in Smoothness of road surface and Number of lanes are not significantly different between in-bound and out-bound road users. These two attributes are relatively the same in both directions. Smoothness of road surface is controlled to be with in the acceptable standard. Thereby, smoothness of the road surface is not an issue for road users. In addition, both directions have four traffic lanes. However, other items, related to road user satisfaction on motorway route 7 , have significance level less than 0.1 , so the mean satisfaction level in those items are different between in-bound and out-bound users. Observe that the mean satisfaction levels of in-bound road users are lower than out-bound in every item.

In order to make road users equally happy in both directions, a highway authority is suggested to take a closer look at in-bound direction travelling to Bangkok. Satisfaction level of in-bound direction is suggested to be improved in each attribute. Moreover, on the descriptive statistics, the mean differences are considered in each attribute and it is found that the biggest difference of 0.27 is on the number of public toilets. In bound direction currently has the same number of toilets as the out-bound; 
however, its traffic congestion is higher than out-bound and number of visitors is higher, so public toilets are not enough for in-bound road users.

In accordance, to the study road users' satisfaction evaluation has been prioritizing in other countries, this is an important mechanism to elevate road infrastructure and should periodically evaluate to catch up with the demands [9]. Comparing to Thailand, the study of road structure development may be a new concept that should be supporting to raise the road infrastructure serviceability.

\section{Conclusion and Future Research}

Motorway route 7 is one of the most important road networks that connects Bangkok and Eastern region together. The overall satisfaction from 890 samples is 3.30. The overall mean satisfaction level of out-bound direction from Bangkok - to Eastern region is higher than the in-bound direction. Two variables of Smoothness of road surface and Number of lanes do create the same mean satisfaction level. The collaborative between government organizations responsible for Tourism and Infrastructure Development is important. The highway authorities of motorway are responsible to create a safe environment for road users and provide service to them in order to maximize the satisfaction level since all motorway road users has to pay the toll fee of between $30-120$ Thai Bath (approximately RM 3 - RM12). Users are expected much more when they have to pay the toll fees. Raising the serviceability level of highway authorities certainly can support the Tourism industry. In this study, the results can be served as a guideline to highway authorities to place their emphasis on improving the service on the in-bound direction first. They are suggested to invest their maintenance budget on the items that receive low level of satisfaction; in particular, the amenities such as the cleanliness of public toilets. Safety is also a main concern for road users as they rated the satisfaction level of less than 3 on average.

In the future, advance statistical method such as logistics regression is recommend to further investigate significant factors that influence on road users who are satisfied while use the service on motorway route 7 and determine significant factors influencing road users who are dis-satisfied.

\section{Acknowledgement}

This research is conducted by partially supported by Sirindhorn International Institute of Technology and Transportation Research Center (TREC). The authors would also like to acknowledge the cooperation from the Inter-city Motorway Division, Department of Highways.

\section{References}

1. R. Turner, Travel\& Tourism Economic Impact 2013, Thailand, World tourism \&Travel council, World tourism \&Travel council, (2013)

2. Department of Tourism, Department of Tourisms Visions/ Missions, Available online: www.tourism.go.th, (2013)

3. J. Blanke, T. Chiesa, The travel and tourism competitiveness report, World Economic Forum, (2013)

4. E. Andrijcic, Y.Y. Haimes, T. Beatley, Public policy implications of harmonizing engineeringtechnology with socio-economic modelling: Application to transportation infrastructure management, Transportation Research, 50, 62-73 (2013)

5. S. Suanmali, K. Chankao, P. Korbsanthia, V. Ammarapala, Factors Affecting Road Users' Satisfaction: the Case of Motorway Route 7. Submitted paper prepared for the publishing at Songklanakarin Journal of Science and Technology (SJST), 24 March 2014, Songklanakarin University, Thailand, (to be published). 
6. J. Khadaroo, B. Seetanah, Transportation Infrastructure and Tourism Development, Annals of Tourism Research, 34, 1021-1032(2007)

7. S. Suanmali, V. Ammarapala, K. Chankao, Factors Affecting Road Users Satisfaction Level on Thailand's Highway Networks: An Empirical Study on Thailand's Motorway Route 7, Proceedings of the $8^{\text {th }}$ International Congress on Logistics and SCM Systems (ICLS 2013), 5-7 August 2013, Tokyo, Japan, 329-334.

8. T. Sakai, K. Yamada-Kawai, H. Matsumoto, T. Uchida, New Measure of the Level of Service for Basic Expressway Segments Incorporating Customer Satisfaction, Procedia - Social and Behavioral Sci., 16, 57-68 (2011)

9. A.P. Wardhana, K. Ishibashi, M. Kiyota, Consideration of Road Management from the View Points of Long-and Short-Distance Road User's Satisfaction, Civil Engineering Dimension Journal of Civil Engineering Science App., 13, 90-97 (2011)

10. Government of Karnataka PWD, Second Road User Satisfaction Survey in Karnataka, State Highway Improvement Project (KSHIP), India, (2004) 